УДК: 94(100) "03/08”:[093+655]

\title{
МАТЕРИАЛ ДЛЯ ПИСЬМА И КНИГИ В ВИЗАНТИИ IV-IX ВВ.: ПРОИЗВОДСТВО И ТОВАР
}

\author{
Е. С. Сорочан
}

Сорочан К. C. Матеріал для письма та книги у Візантії IV-IX ст.: виробництво і товар. У статті розглядається виробництво і торгівля матеріалом для письма (папірус, пергамен, папір) та книгами у ранньосередньовічній Візантійській імперії IV-IX ст. Особливу увагу приділено професійній спеціалізації в цій торгово-ремісничій сфері. Уточнено професійну діяльність хартопоїв, мембранопоїв, вівліокапілосів, переписувачів, палітурників та художників.

Ключові слова: Візантія; матеріал для письма; книги; папірус; пергамен; папір; хартопой; мембрано пой; вівліокапілос.

Сорочан E. C. Материал для письма и книги в Византии IV-IX вв.: производство и товар. В статье рассматривается производство и торговля писчим материалом (папирус, пергамен, бумага) и книгами в раннесредневековой Византийской империи IV-IX вв. Основное внимание уделено профессиональной специализации в этой торгово-ремесленной сфере. Уточнена профессиональная деятельность хартопоев, мембранопоев, вивлиокапилосов, переписчиков, переплетчиков и художников.

Ключевые слова: Византия; материал для письма; книги; папирус; пергамен; бумага; хартопой; мембранопой; вивлиокапилос.

Sorochan K. S. Material for Writing and Books in Byzantium of 4th-9th Centuries: Producing and Goods. The article is devoted to producing and trade of writing materials (papyrus, parchment, paper) and books in the early medieval Byzantine Empire in 4th-9th centuries. Special attention is paid for professional specialization in this craft-commercial field of economics. There is specified professional activity

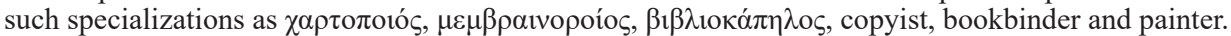

Keywords: Byzantium, writing material, books, papyrus, parchment, paper, chartopoios, membranopoios, vivliokapilos.

Византийская империя во всевремена обладаламногочисленнымиправительственными и муниципальными учреждениями, канцеляриями, нотариями, тавуллариями, активно осуществлявшими делопроизводство и документооборот. В свою очередь, частная жизнь грамотных ромеев включала чтение книг, развитие образования, переписку. В любом случае необходимым компонентом деловой жизни являлся материал для письма и книги, которые выступали не только как объект производства определенных специалистов, но и как объект рыночной торговли ${ }^{1}$.

Материал для письма в Византии подразделялся на три основные категории: папирус, пергамен (самый дорогой) и бумагу. Для чернового письма использовали простые,

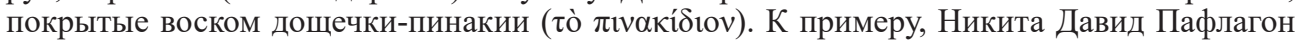
упоминал человека с именем $\pi \imath \alpha \kappa \tilde{\alpha} \varsigma$, дословно - того, кто изготовлял пинакии ${ }^{2}$.

Эдикт о ценах 301 г. называет два основных на тот период писчих материала, изготовлявшихся вручную и поступавших на рынок - пергамен и дешевый папирус ${ }^{3}$. Несмотря на перебои с поставками папируса, особенно ощутимые со второй половины VII в., в Византии папирус продолжали использовать для ведения документации до IX в. ${ }^{4}$. Бумага, китайское изобретение, проникла в империю уже к VII в., подтверждением чему служат материалы 14 канона VI Вселенского собора. Однако в активное использование она вошла не ранее IX в., когда василевсом Никифором I был даже установлен специальный на-

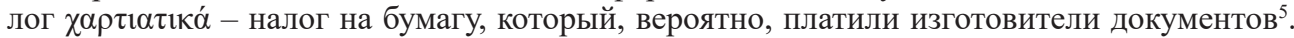
До XIII в. был распространен восточный тип бумаги ( $\beta \alpha \mu \beta \alpha ́ \kappa 10 v)$ на основе хлопка без водяных знаков, которая стоила как минимум в половину дешевле пергамена ${ }^{6}$. Примечательно, что все самые ранние императорские документы были написаны именно на бумаге. Поэтому категорично говорить о ее использовании в Византии не ранее 1050-х гг. нет оснований ${ }^{7}$. 


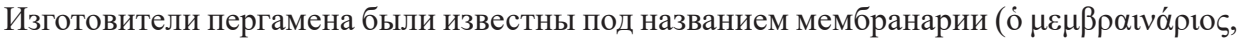
o $\mu \varepsilon \mu \beta \rho \alpha ́ i ̈ v o \varsigma)^{8}$. Термин хартопрат (ó $\left.\chi \alpha \rho \tau о \pi \rho \alpha ́ \tau \eta \varsigma\right)$, встречающийся в ранневизантийских папирусах из Египта, И. Ф. Фихман переводил как «торговец папирусом» ${ }^{9}$, очевидно, учитывая специфику региона, хотя это мог быть и продавец пергамена или бумаги. Г. Г. Литаврин в комментариях к труду Константина Багрянородного «Об управлении империей» называл хартопоев изготовителями пергамена. Э. Кирстен, знаток ранневизан-

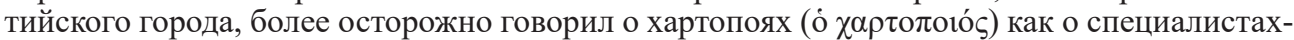
ремесленниках по изготовлению «харт», не уточняя, из чего последние были сделаны ${ }^{10}$. По мнению Р. Дженкинза, это были изготовители пергамена, а по мнению Н. Икономидеса, - бумаги ${ }^{11}$. Во всяком случае, Феодор Студит различал в своих письмах и сочинениях хартопоев и мембранопоев (ó $\mu \varepsilon \mu \beta \rho \alpha 1 v o \rho o i ́ \varsigma))^{12}$, и, значит, с точки зрения ромеев они делали разную продукцию. В указанном выше 14 каноне VI Вселенского собора, состоявшегося в Константинополе в 680 / 681 гг., бумага и пергамен противопоставлялись как два разных, одновременно находившихся в обращении писчих материала: речь шла о «древних бумажных книгах» V Вселенского синода 553 г., а также «двух книгах на кожах и бумажном свитке седьмого деяния», а далее уточнялось, что в «подлинном бумажном свитке святого пятого собора» - «латинской книге в седьмом деянии есть пропуск сравнительно с бумажным свитком» ${ }^{13}$.

Схолия времен Льва VI (886-912 гг.) к разделу Василик о правилах составления актов поясняла, что для изготовления хартий - письменных документов, наряду с иным древесным материалом (ं்

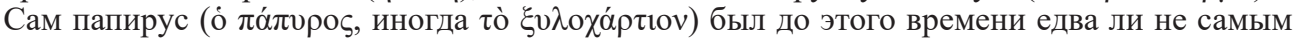
распространенным писчим материалом. В таком случае хартопои могли специализироваться на производстве любого вида писчего материала, тогда как мембранопои, судя по прозрачной этимологии названия их профессии, выделывали для письма только натуральную кожу (ं่ $\mu \varepsilon \mu \beta \rho \alpha ́ v \alpha)$. Она отличалась эластичностью, поскольку, как показывают специальные исследования материала, при окончательной обработке византийского пергамена применяли белок яйца и углеводную слизь, скорее всего, отвар льняного семени, а также квасцы (благодаря тому, что эти соли трехвалентных металлов вызывают денатурацию белков, квасцы использовали как дубящее средство $)^{15}$.

Учитывая высокий спрос на писчий материал для многочисленных государственных учреждений, вполне объяснимо привилегированное положение хартопоев, которые иногда освобождались от внесения военных сборов, экстраординарных налогов ${ }^{16}$.

И хартопои, и мембранопои изготавливали материал для создания будущих книг. Ранняя византийская агиография содержит примеры того, как на рынке, причем не только городском, но и сельском, можно было в любой момент найти покупателя на книгу и получить, таким образом, деньги ${ }^{17}$. Иоанн Хрисостом упрекал тех, кто «...приобретают книги не для пользы, а для того, чтобы выказать этим свое богатство и похвастать», отмечая при этом, что книги были ценной редкостью: «Игральные кости можно найти у весьма многих, а книг нет ни у кого, или у немногих» ${ }^{18}$. Чаще всего в источниках фигурируют сведения о переписке и продаже Библии или ее части, Нового Завета, Псалтири - дорогих покупках, стоивших в среднем от одного до 20-30 солидов, разом выложить которые мог позволить себе не каждый ${ }^{19}$. Украшенная золотой росписью и миниатюрами, нотной записью и другим декором книга стоила в несколько раз дороже. Интересно, что стоимость пергамена, составлявшая 23-38\% от общей стоимости книги, зависела еще и от плотности письма, то есть - труда переписчика ${ }^{20}$. Особенно популярной в VIII-IX вв. стала Псалтирь, которая служила не только для нужд личного благочестия, но и для обоснования идейных позиций и иконоборцев, и иконопочитателей, активно прибегавших к ней ${ }^{21}$. Писцы, переписывавшие такие книги в течение поста, особенно - восьми недель Великого Поста, пользовались самой лучшей репутацией, но это же обстоятельство указывает на то, что в такое время спрос на пергамен достигал максимума, тем более, что его было трудно восполнить изза сокращения забоя скота, шкуры которого шли на производство пергамена ${ }^{22}$. Так или иначе, в раннесредневековой Византии к IX в. существовал устойчивый книжный рынок

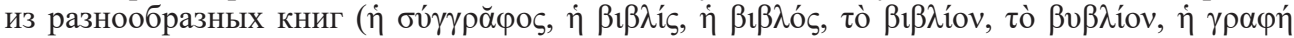

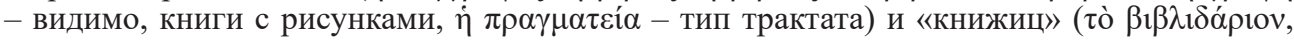

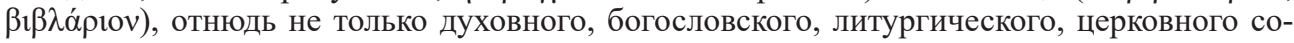


держания, которые изготовляли книгописцы - вивлиографы (ó $\beta 1 \beta \lambda \iota \gamma \rho \alpha ́ \alpha \rho \varsigma)$, каллиграфы

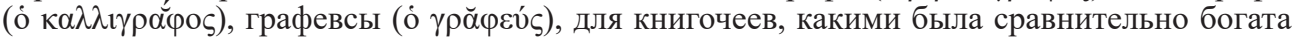
империя, выгодно отличавшаяся в это время от королевств Западной Европы ${ }^{23}$. Примечательно, что тогда же ромеями была выработана новая, более экономная форма книжного письма - минускул и новые каллиграфические правила.

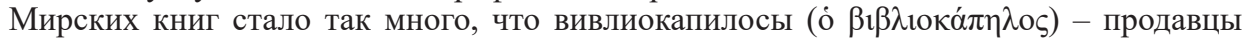
книг, и мирепсы - торговцы благовониями, лекарствами и москательными товарами, не пренебрегали использовать их в расчлененном виде, прежде всего, испорченные чем-либо листы, пуская на обертку товаров, на что сетовало 68 правило Вселенского синода 691 / 692 гг. Это правило запрещало «портить, или разрывать, или отдавать книготорговцам, или так называемым мироварам (мирепсам), или кому другому для уничтожения книг Ветхого и Нового Завета, также книг святых и признанных наших проповедников и учителей, разве какая от моли, или от воды, или от чего другого сделается совершенно негодной к употреблению», за что грозило годичное отлучение от Церкви, причем это касалось и «покупающего такие книги» ${ }^{24}$. Нетрудно заметить, что с прочими, не духовными книгами можно было поступать как заблагорассудится. Даже окраинные провинциальные ромейские города являют довольно многочисленные находки следов таких книг - остат-

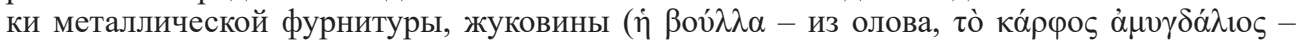
деревянные, миндалевидной формы), уголки, средники кожаных и деревянных переплетов, литые или кованые бронзовые застежки, кинжаловидные шпеньки, а также железные секирообразные ножи с лезвием полукруглой формы, которые служили как для обработки, шлифовки пергамена, так и для подрезки листов, зачистки неровностей ${ }^{25}$.

Судя по иконографическим образцам и следам на писчем материале, в особом инструментарии, который необходимо было приобретать, нуждался сам писец и книжный художник. Это были каламы (ó ко́ $\lambda \alpha \mu \rho \varsigma)$ - тростниковые заостренные палочки для письма, перья гусиные, лебединые, индюшиные из крыла птицы, часто со срезанным опереньем, серебряные или свинцовые стилосы - штифты, перочинные ножи с кривыми или прямыми лезвиями, ножи с полукруглым лезвием, линейки, циркули для разметки, губки, куски пемзы, красители (киноварь, свинцовый сурик, ляпис-лазурь) и цветные либо черные чернила на основе угля, танина в пузырьках, даже порошковое серебро, полупрозрачный лак, возможно, кармин (из насекомых под названием кермес), палитры, раковины, кисти, полировальные камни ${ }^{26}$. Впрочем, кто их изготовлял и готовил к работе, остается неизвестным. Едва ли это были предметы узкоспециализированной торговли. Их можно было купить в готовом виде.

Торговцы книгами, вивлиокапилосы, работали в Константинополе в тех книжных лавках - политирах ( в портиках Большого императорского дворца ${ }^{27}$. Наряду с ними изготовлением книг, главным образом, на заказ, и их продажей обеспечивали себе доход упомянутые выше

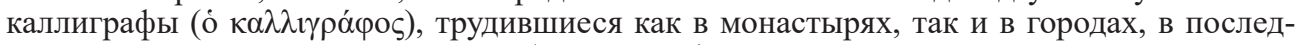
нем случае, как представители «свободных профессий», даже женщины, к слову, неплохо зарабатывавшие ${ }^{28}$. К примеру, пергамен для сочинений Платона из 432 страниц, каждая 32,5 х 22,5 см, в 895 г. стоил 8 золотых номисм, а переписка $-13^{29}$.

В Византии книжное дело не стало монополией монастырских мастерских письма, как это случилось на раннесредневековом Западе, но на основании примеров, почерпнутых из византийской агиографической литературы VIII-IX вв., можно заключить, что большин-

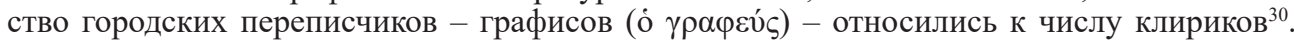
Видимо, они не все готовили книгу от начала до конца. Другими словами, процесс изготовления рукописи мог быть разделен среди разных специалистов, причем зачинателями в разделении труда в этом деле, как и на Западе, стали монашеские коллективы. В столичном Студийском монастыре, судя по уставу его настоятеля Феодора Студита, в первой чет-

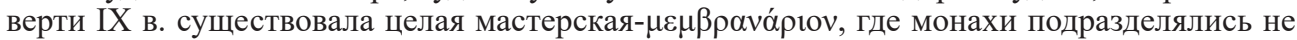

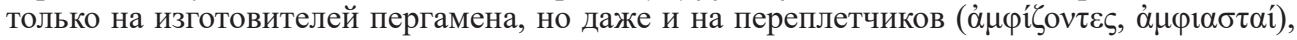
а сам Феодор Студит, находясь в изгнании, зарабатывал на жизнь не только переписывая книги, но и рисуя в них за плату миниатюры, то есть работая художником-миниатором ${ }^{31}$. Но отсутствие строгой специализации делает также вероятным предположение, что пергаменщики могли одновременно делать собственно книги, сшивать их из рукописных те- 
традей и даже ювелирно украшать переплеты костью, драгоценными камнями, эмалью 32 . В частности, достаточно ясный намек на это прослеживается в «Трактате об окраске мозаик», где автор постоянно обращается к одному читателю и предлагает ему заниматься всеми видами крашения, золочения, выделкой золотого листа, пергамена, изготовлением стекла, смальты и даже самому добывать исходный материал ${ }^{33}$.

Итак, производство писчего материала (папируса, пергамена, бумаги) в раннесредневековой Византии было сосредоточено в руках профессионалов - хартопоев и еще более узких специалистов - мембранопоев, изготовителей пергамена и, возможно, собственно книг из него, тогда как торговля разнообразной книжной продукцией перешла в VI-VII вв. от вивлиокапилосов преимущественно к переписчикам (вивлиографам, графевсам, каллиграфам), которые в некоторых случаях разделяли свой труд с переплетчиками - амфизонтами, амфиастами и художниками - иллюстраторами, зографами. Спрос на рукописные книги в Романии никогда не исчезал и стал расти к IX в., что было вызвано и нуждами иконоборской полемики, и последующим подъемом образования, закрепившим за книгами значение распространенного, хотя и весьма ценного предмета устойчивой рыночной торговли.

${ }^{1}$ Cp.: Constantini Porphyrogeniti De administrando imperio. London, 1962. Vol. 2: Commentary by F. Dvornik, R. J. Н. Jenkins, B. Lewisetal. P. 205; Фихман И. Ф. Оксиринх - город папирусов. М., 1976. C. 130.

${ }^{2}$ Nicetae Davidae Paphlagonae Vita Sti Ignatii // Patrologiae cursus completus. Patrologiae graeca / [Ed. J.-P. Migne]. 1864. T. 105. Col. 544.

${ }^{3}$ Diocletians Preisedikt. Texte und Kommentare / Hrsg. von S. Lauffer. Berlin, 1971. S. 7.8, 35.1.

${ }^{4}$ CM.: Dölger F. Byzantinische Diplomatik. 20 Aufsätze zum Urkundenwesen der Byzantiner. Speyer an Rhein, Ettal, 1956.

${ }^{5}$ Oikonomides N. Fiscalite et exemption fiscale a Byzance (IXe-XIe s.). Athenes, 1996. P. 138; Oikonomides N. Writing Materials, Documents, ans Books // Economic History of Byzantium from the Seventh through the Fifteenth Century / Ed.-in-Chif A.E. Laiou. Washington, D.C., 2002. P. 577-580.

${ }^{6}$ Oikonomides N. Writing Materials, Documents, and Books // The Economic History of Byzantium: From the Seventh through the Fifteenth Century / Editor-in-Chief Angeliki E. Laiou. Washington, D.C., 2002. P. 590.

${ }^{7}$ Ср.: Оксфордское руководство по византинистике / Ред. Э.Джеффрис, Дж.Хэлдон, Р.Кормак; пер. с англ. В. В. Швец; гл. ред. С. Б. Сорочан; ред. А. Н. Домановский, П. Е. Михалицин, А. Г. Чекаль. Вып. 1. Харьков, 2014. С. 470.

${ }^{8}$ Daris $S$. Il lessico latino nello lingva greca d'Egitto // Aegyptus. Rivista italiana di egittologia e di papirologia. Milano, 1960. T. 40. P. 177-314, s.v. membranarios.

${ }_{9}^{9}$ Фихман И. Ф. Египет на рубеже двух эпох. М., 1965. С. 32.

${ }^{10}$ Kirsten E. Die byzantinische Stadt // Berichte zum XI. Internationalen Byzantinisten-Kongress, München: Beck, 1958. Bd. 1. S. 27.

${ }^{11}$ Cм.: Oikonomides N. The Social Structure of the Byzantine Countryside in the First Half of the 10th Century // Symmeikta. Athena, 1996. T. 10. P. 117.

${ }^{12}$ Липшии Е. Э. К вопросу о городе в Византии в VIII-IX вв. // Византийский временник. 1953. T. 6. C. 122.

${ }^{13}$ Деяния Вселенских соборов. СПб., 1996. Т. 4: VI собор. VII собор. С. 199, 201.

${ }^{14}$ Basilicorum libri LX / Ed. C. G. E. Heimbach, G. E. Heimbach. Lipsiae, 1840. T. 2 (Lib. XIIIXXIII). XXII. 2, schol. 6.

${ }^{15}$ Мокрецова И. П., Наумова М. М., Киреева В. Н., Добрынина Э. Н., Фонкич Б. Л. Материалы и техника византийской рукописной книги. М., 2003. С. 22-23.

${ }^{16} \mathrm{Cp} .:$ Константин Багрянородный. Об управлении империей: Текст, пер., коммент. / Под ред. Г. Г. Литаврина, А. П. Новосельцева. М., 1989. Гл. 52. 10-11. С. 244.

17 Палладия, еп. Еленопольского Лавсаик, или повествование о жизни святых и блаженных отцов / Пер. с греч. М., 1992. С. 158. Гл. 99; С. 159. Гл. 100.

${ }^{18}$ Иоанн Златоуст. Беседы на Евангелие от св. ап. Иоанна Богослова. XXXII. 3 // Иже во святых отца нашего Иоанна архиепископа Константина града Златоустого избранные творения. Собрание поучений. Сергиева Лавра, 1993. Кн. 1.

${ }_{19}$ Сократ Схоластик. Церковная история. М., 1996. С. 189 (IV. 23); Appendix ad Palladii Helenopolitani episkopi Apophthegmata patrum // Patrologiae cursus completus. Patrologiae graeca / [Ed. J.-P. Migne]. 1858. T. 65. Col. 145 C; Beati Ioannis Eucratae liber quiinscribitur Pratum... // Patrologiae cursus completus. Patrologiae graeca / [Ed. J.-P. Migne]. Turnholti, 1976. T. 87 C. Col. 2997; Symeoni 
Logothetae Metaphrastae Vita Sti Ioanni // Patrologiae cursus completus. Patrologiae graeca / [Ed. J.-P. Migne]. 1864. T. 114. Col. 569; Ostrogorsky G. Löhne und Preise in Byzanz // Byzantinoslavica. 1932. Bd. 32. Н. 1-2. S. 326; Сорочан С. Б. Византия IV-IX веков: этюды рынка. Харьков, 1998. С. 386-387.

${ }^{20}$ Oikonomides N. Writing Materials, Documents, and Books // The Economic History of Byzantium: From the Seventh through the Fifteenth Century / Editor-in-Chief Angeliki E. Laiou. Washington, D.C., 2002. P. 591. C. 24

${ }^{21}$ Залесская В. Н. Прикладное искусство Византии IV-XII веков. Опыт атрибуции. СПб., 1997.

${ }^{22}$ Rapp C. Holy texts, holy men and holy scribes: aspects of scriptural holiness in late antiquity // The Early Christian Book / Ed. by W. Klingshirn, L. Safran. Washington, DC, 1991. P. 194-222.

${ }_{23}$ Ср.: Истрин В. М. Хроника Георгия Амартола в древнем славянорусском переводе. Л., 1930. Т. 3: Греческо-славянский и славянско-греческий словари. С. 250; История Византии. М., 1967. Т. 1. С. 379-394; Т. 2. С. 80-87, 354-355, 357-360; Каждан А. П. Книга и писатель в Византии. М., 1973. С. 32-36, 43 сл., 130-140; Roberts C. H., Skeat T. C. The Birth of the Codex. London, 1983; Культура Византии. М., 1984. С. 478-503: Культура Византии. М., 1989. С. 365-395; Cavallo G., Maehler H. Greek Bookhands of the Early Byzantine Period, A.D. 300-800. London, 1987. P. 19; Hunger H. Schreiben und Lesen in Byzanz. Die byzantinische Buch-Kultur. München, 1989. S. 21.

24 Деяния Вселенских соборов. СПб., 1996. Т. 4: VI собор. VII собор. С. 291.

${ }^{25}$ См.: Сорочан С. Б. Византийский Херсон... Ч. 2. С. 1148-1149. Рис. 460-461.

${ }_{26}^{26}$ Мокрецова И. П. Материалы и техника византийской рукописной книги. М., 2003. С. 26-27; Оксфордское руководство по византинистике / Ред. Э. Джеффрис, Дж. Хэлдон, Р. Кормак; пер. с англ. В. В. Швец; гл. ред. С. Б. Сорочан; ред. А. Н. Домановский, П. Е. Михалицин, А. Г. Чекаль. Вып. 1. Харьков, 2014. С. 472.

${ }^{27}$ Агафий. О царствовании Юстиниана / Вступ. ст., пер., прим. М. В. Левченко. М., 1953. С. 64 (II. 29); Сорочан С. Б. Византия IV-IX веков: этюды рынка. Харьков, 2001. С. 214.

${ }^{28}$ Palladio. La Storia Lausiaca / Introd. di Ch. Mohrmann, testo critico e commento a cura di G. J. M. Bartelink, trad. di M. Barchiesi. Roma, 1974. Sec. XXXII; Mansi J. D. Sacrorum consiliorum nova et amplissima collectio. Florentiae et Venetiis, 1759-1798. T. 11. Col. 596; Оксфордское руководство по византинистике / Ред. Э. Джеффрис, Дж. Хэлдон, Р. Кормак; пер. с англ. В. В. Швец; гл. ред. С. Б. Сорочан; ред. А. Н. Домановский, П. Е. Михалицин, А. Г. Чекаль. Вып. 1. Харьков, 2014. С. 472.

${ }^{29}$ Wilson N. Books and readers in Byzantium // Byzantine Books and Bookmen. Washington, D.C., 1975. P. 3.

${ }^{30}$ Stephanus Constantinopolitanus Diaconus in vitam et martyrium beatissimi et sancti martyris Stephani Junioris... // Patrologiae cursus completus. Patrologiae graeca / [Ed. J.-P. Migne]. 1864. T. 100. Col. 1097; Vita Methodii patriarchi Constantinopolinarum // Patrologiae cursus completus. Patrologiae graeca / [Ed. J.-P. Migne]. 1865. T. 100. Col. 1253; Житие иже во святых отца нашего Феодора Едесского / Изд. И. Помяловского // Записки СПб. ун-та. Истор.-филол. фак-т. СПб., 1892. С. 13.

${ }^{31}$ Липшии Е. Э. К вопросу о городе в Византии в VIII-IX вв. С. 122; Eleopoulos N. X. E Bibliotheke kai to bibliographokon ergasterion tes mones tou Stoudiou. Athenai, 1967; Сюзюмов М. Я. Византийский город (середина VII - середина IX в.) // Византийский временник. 1967. Т. 27. С. 66, прим. 95; Оксфордское руководство по византинистике / Ред. Э. Джеффрис, Дж. Хэлдон, Р. Кормак; пер. с англ. В. В. Швец; гл. ред. С. Б. Сорочан; ред. А. Н. Домановский, П. Е. Михалицин, А. Г. Чекаль. Вып. 1. Харьков, 2014. С. 468.

${ }^{32}$ Lowden J. The Word made Visible: the exterior of the early Christian book as visual argument // The Early Christian Book / Ed. by W. Klingshirn, L. Safran. Washington, DC, 2007. P. 13-47.

${ }^{33}$ См.: Бородин О. Р. Равеннский экзархат. Византийцы в Италии. СПб., 2001. С. 266. 